\title{
Quantitative Ballistocardiography (Q-BCG) for Measurement of Cardiovascular Dynamics
}

\author{
Z. M. TREFNÝ ${ }^{1}$, J. SVAČINKA ${ }^{1}$, O. KITTNAR ${ }^{2}$, J. SLAVÍČEK ${ }^{2}$, M. TREFNÝ ${ }^{1}$, \\ E. FILATOVA ${ }^{1}$, J. A. TICHÝ ${ }^{1}$, P. SMRČKA ${ }^{3}$, M. STORK ${ }^{4}$, M. LOUČKA $^{5}$
}

${ }^{1}$ Laboratory of Cardiology, Prague, Czech Republic, ${ }^{2}$ Institute of Physiology, First Medical Faculty, Prague, Czech Republic, ${ }^{3}$ Faculty of Biomedical Engineering, Czech Technical University in Prague, Prague, Czech Republic, ${ }^{4}$ Charles University, Plzeň, Czech Republic, ${ }^{5}$ Department of Mathematics, Institute of Chemical Technology, Prague, Czech Republic

Received March 17, 2010

Accepted March 10, 2011

On-line May 16, 2011

\section{Summary}

In the seventies of the past century ballistocardiography had been thought to be obsolete in cardiology for impossibility of objective calibration. In the present work the quantitative ballistocardiography (Q-BCG) for measurement of systolic force (F) and minute cardiac force (MF) in sitting subject was described. The new principle of piezoelectric transducer enabled to register the force caused by the heart and blood movement, which was not measured before. The calibration proved that the action of the force on the transducer was expressed quantitatively without the amplitude-, time-, and phase deformation. The close relationship of skeletal muscle force and $F$ was proved. The F and MF changed under different physiological conditions (age, partial pressure of oxygen, body weight, skeletal muscle force). It was shown that the systolic force (F) and minute cardiac force (MF) are the physiological parameters neurohumorally regulated similarly as the heart rate or systolic volume.

\section{Key words}

Quantitative ballistocardiography • Systolic force • Minute cardiac force $\bullet$ Cardiovascular dynamics $\bullet$ Human heart

\section{Corresponding author}

Z. M. Trefný, Laboratory of Cardiology, U Průhonu 52, 17000 Prague 7, Czech Republic. Fax: $+420-2-220878403$. E-mail: z.m.trefny@grbox.cz

\section{Introduction}

The movement of the heart and blood is a primary source of the force acting on the body. The first report on cardiac and blood motion has been written in 1628 by William Harvey. The first record of such a movement of the body was made by Gordon (1877) with a bed suspended from the ceiling (Henderson 1905, Nickerson and Curtis 1944). The ballistocardiography (BCG) was used for measurement of cardiac output in the first half of 20th century (Hamilton et al. 1945). The method studying the cardiac output was presented in American Physiological Society by Isaac Starr in 1936 (Hamilton 1962, Starr and Noordergraaf 1967). The ballistocardiographs had the frequency similar to the frequency of the heart rate which decreased the practical use of the method (Jackson 1972). The ballistocardiographs were capable to measure displacement $(\mathrm{mm})$, the velocity $(\mathrm{mm} / \mathrm{s})$ and the acceleration $\left(\mathrm{mm} / \mathrm{s}^{2}\right)$ of motion of the body.

We were interested 1) whether the new method using the piezoelectric transducer enables to register the force of the heart and blood movement which was not measured until now; 2) whether it is possible to calibrate the action of force on transducer to obtain the quantitative expression of the force; 3 ) whether the relation of skeletal muscle force and systolic force (F) is present; 4) we tried to show in several examples that the method of quantitative ballistocardiography (Q-BCG) is capable to measure the quantitative changes of forces caused by the 
cardiovascular activity in different physiological conditions.

\section{Methods}

\section{Quantitative ballistocardiograph (Q-BCG)}

The portable quantitative ballistocardiograph (Fig. 1) consists of a seat, supported at three points. The two front supports are rigid. The rear one, on which the center of gravity of the body is vertically projected, is a piezoelectric transducer (Trefný and Smetánka 1956, Trefný 1962, Trefný and Wagner 1965, 1966). The patient is examined in a sitting position.

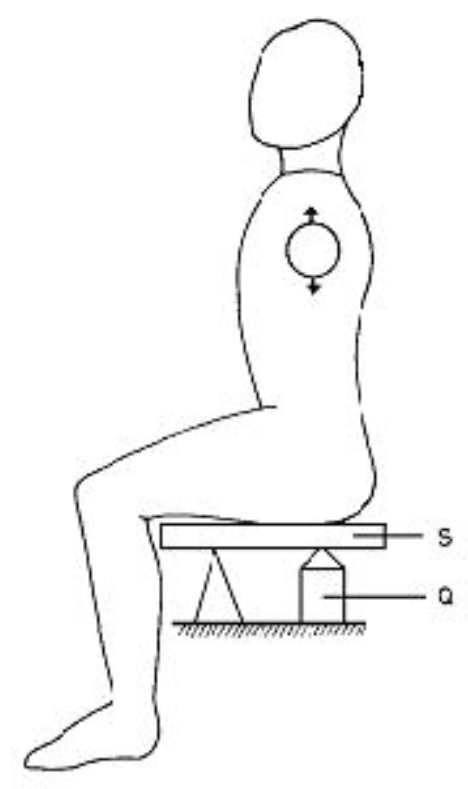

Fig. 1. Scheme of portable quantitative ballistocardiograph. $\mathrm{S}-$ seat, $\mathrm{Q}$ - piezoelectric transducer.

Our pick-up device, bearing structure of convenient properties, a sitting position of the examined person in close contact with the seat and a transistor amplifier with a sufficiently long time constant reduce and suppress the possibility of form-, phase- and time distorsion of the registered curves. The natural frequency of the ,very high frequency“ (VHF) - chair is higher than $1000 \mathrm{~Hz}$ so there is no interference with the vibrations caused by the heart activity. Neither damping nor isolation from building vibrations are necessary. These properties enabled us to calibrate our ballistocardiographic system and to determine the absolute value of force acting upon the pick-up device. The amplitude of the individual waves can be measured in units of force. For easier operation it is important that the total weight of the whole apparatus is only $5.5 \mathrm{~kg}$ which renders it portable.

The cardiac forces act on the piezoelectric transducer. It is the principle of Q-BCG method, which is capable to register the forces. There is no other similar method to measure it.

The mathematical analysis of the ballistocardiographic system and the calibration of apparatus was described (Trefný and Wagner 1967). The use of Q-BCG enabled us to introduce new characteristic quantities of the systolic force (F) and the minute cardiac force (MF) which are related to the body weight of each subject in order to obtain comparable values.

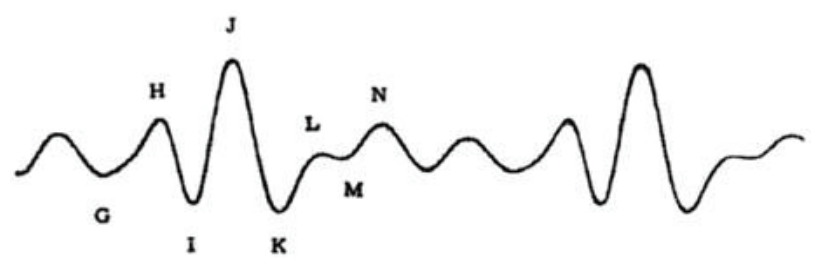

Fig. 2. Record of the very high frequency (VHF) quantitative ballistocardiogram (Q-BCG) in a normal man, age 42 years, $63 \mathrm{~kg}$. Nomenclature of deflections based on revised criteria proposed by the committee on BCG terminology of the American Heart Association, Circulation 14: 435-450, 1956. Paper speed $50 \mathrm{~mm} / \mathrm{s}$. HI, IJ, JK - ballistocardiographic amplitudes.

The systolic force $(\mathrm{F})$ is the arithmetic mean of the forces measured from the ballistocardiographic amplitudes HI, IJ and JK from Q-BCG curve (Fig. 2, Trefný 1970). The systolic force (F) represents the force response caused by the heart activity and is expressed in unites of force $(\mathrm{N})$. In order to get a measure for the total intensity of the heart activity, we introduced the minute cardiac force (MF) which equals the systolic force (F) multiplied by the heart rate (HR) and which is expressed in units of force per min. The physical properties of the portable quantitative ballistocardiography were described (Trefný and Wagner 1965). We measured the relationship between the frequency of acting force and the amplitude of measured force (Fig. 3). The relationship between the amplitude of acting force and the amplitude of measured force was linear in the measured range from 0.1 to $4 \mathrm{~N}$ (Fig. 3, left part). In the frequency range from 0.1 to $60 \mathrm{~Hz}$ the amplitude of force measured in four different values did not depend on the changes of frequency of acting force (Fig. 3, right part). From these results it is evident that our ballistocardiograph needs neither amplitude, nor phase correction of the measured force. It was proved that our ballistocardiographic apparatus is 

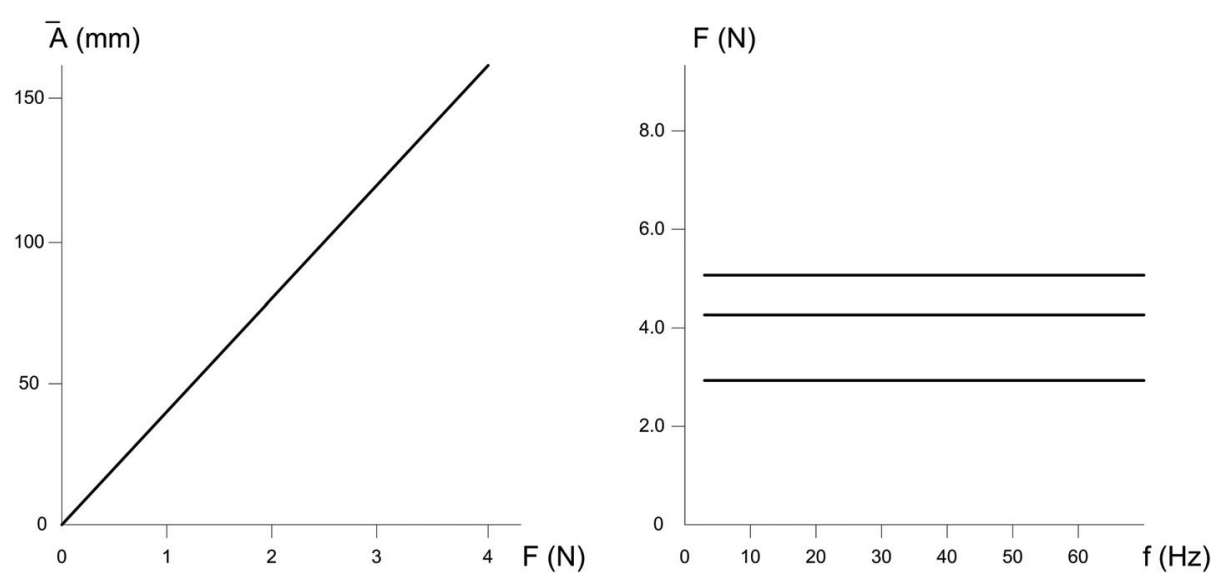

Fig. 3. Left part - Relationship between the amplitudes $(\mathrm{mm})$ of actual and recorded exciter forces (Newtons). The force of $1 \mathrm{~N}$ changed the amplitude of Q-BCG signal for $10 \mathrm{~mm}$. The exciter forces increased fluently and the recorded amplitude increased also fluently in linear dependence, that is why no point are present. Right part - Relationship between recorded exciter force (Newtons) and frequency for four constant amplitudes of excitation. able to measure and to record the forces quantitatively in the frequency range $0.1-60.0 \mathrm{~Hz}$ without any practical distortion (Fig. 3, Trefný et al. 1970, 1972). The calibration of Q-BCG: a force of 1 Newton changed the amplitude of the Q-BCG to $10 \mathrm{~mm}$. The force of the heart and blood motion was expressed in Newtons (the systolic force $(\mathrm{F})$ and the minute cardiac force $(\mathrm{MF})$ were measured by Q-Euro-seismo-cardio-T, GETA Ltd).

\section{Echocardiography}

By the echocardiography we measured the ejection fraction. The ratio E/A (early diastolic filling velocity $\mathrm{E}$ and late diastolic - atrial - filling velocity $\mathrm{A}$ ) and the maximum velocity of the blood flow in ascendent aorta $\mathrm{V}_{\text {maxao }}$ were measured by Image Point Ultrasound System Hewlett Packard.

\section{Thoracic electrial bioimpedance (TEB)}

The TEB method was used for measurement of ejection fraction (EF, \%), contractility index ( $\mathrm{IC}$ in $\mathrm{ml} / \mathrm{s}$ ) and acceleration index (ACI, ml/ $\mathrm{s}^{2}$ ) by NCCOM 3, BoMed Medical Manufacturing Ltd., Irvine, CA (Šrámek 1993).

\section{The hyperbaric and hypobaric chamber}

The hyperbaric and hyporabic chamber was used for measurement of systolic and minute cardiac force in different oxygen pressure conditions. Ten healthy men (age 20 \pm 2 years) were examined by Q-BCG method in hypobaric chamber in pressure responding to the height of $1500,2500,4000$ and 6000 meters above the sea level. The same chamber was used as hyperbaric one when the air was respired in the presence of 1 Atm (1 ATA), 2 ATA and 3 ATA (10, 20 and 30 meters below the sea level). The pressure of oxygen was from 70 to 2200 torr corresponding to the height 6000 meters and depth to $30 \mathrm{~m}$ below the sea level. The parameters heart rate (HR), F/kg, MF/kg were measured in $6^{\text {th }}$ min in every experiment in inspiratory apnea. The data were transmitted telemetrically (Trefný and Svačinka 1970).

\section{The hand grip force}

was measured by classic manual dynamometer.

\section{Bicycle ergometry}

The duration of three working loads was $5 \mathrm{~min}$, the duration of the last one was $2 \mathrm{~min}$. The interval between the loads was $2 \mathrm{~min}$. The performance (work) of the boys was $60,100,120,240 \mathrm{~W}$, in sedentary men 60 , 120,180 and $300 \mathrm{~W}$ was applied, and in athletes 60, 120, 240 , and $300 \mathrm{~W}$. The frequency of rotation (pedaling frequency) was 60 per min. The heart rate, Q-BCG were examined before, and after finishing of each phase of load, and after experiment (Trefný et al. 1968).

\section{The selection of persons}

For measurement of systolic force $(\mathrm{F})$ and minute cardiac force (MF), different groups of persons were collected:

- 116 boys and 112 girls, age 8-19.5 years (agedependent increase of $\mathrm{F}$ and MF and decrease in $\mathrm{F} / \mathrm{kg}$ and $\mathrm{MF} / \mathrm{kg}$, Fig. 4 and 5);

- 236 men, age 20-60 years (decrease in $\mathrm{F}$ and $\mathrm{F} / \mathrm{kg}$ in adults, Fig. 6);

- 10 men, age $20 \pm 2$ years (military service, relationship between $\mathrm{F} / \mathrm{kg}, \mathrm{MF} / \mathrm{kg}$ and $\mathrm{pO}_{2}$, Fig. 7);

- 42 girls, 8-19.5 years (relationship between $\mathrm{F} / \mathrm{kg}$, ACI, EF, and BMI, BSA Fig. 8);

- 30 boys, $13 \pm 5$ years, 30 sedentary men, $40 \pm 4$ years, 30 athletes, $20 \pm 2$ years (relationship between $\mathrm{F} / \mathrm{kg}$, $\mathrm{MF} / \mathrm{kg}$ and working capacity measured by bicycle ergometer, Fig. 9);

- 49 boys, 8-14 years (relationship between heart weight, hand grip force and systolic force, Fig. 10). 

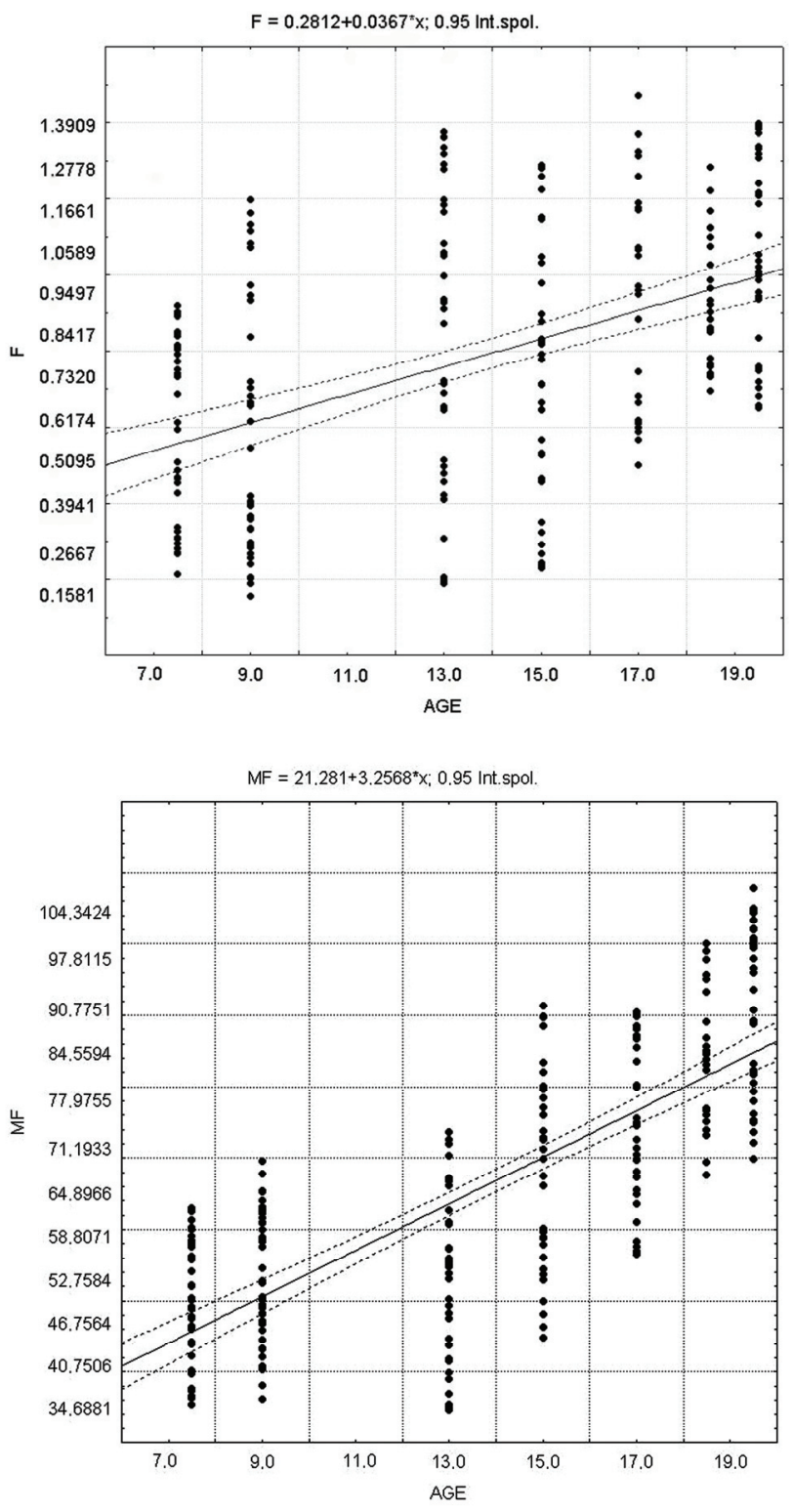

Fig. 4. Age-dependent increase in systolic force (F) (upper part) and minute cardiac force (MF) (lower part) measured in boys by Q-BCG. Abscisse: age (years). Ordinate: systolic force (upper part) in Newtons, right part: minute cardiac force ( $\mathrm{N} / \mathrm{min})$. Increasing linear relationship significance tested by Student test, $p<0.0001$. Predictive equation is given on the head of each graph.

\section{Statistical evaluation}

The Student t-test for two independent collections was used in Figures 4-7, and the Spearmann correlation coefficient in Figures 8 and 10. A more detailed explanation is in each Figure.

\section{Results}

The Figure 4 describes the relationship of age and systolic force (F) and minute cardiac force (MF) in
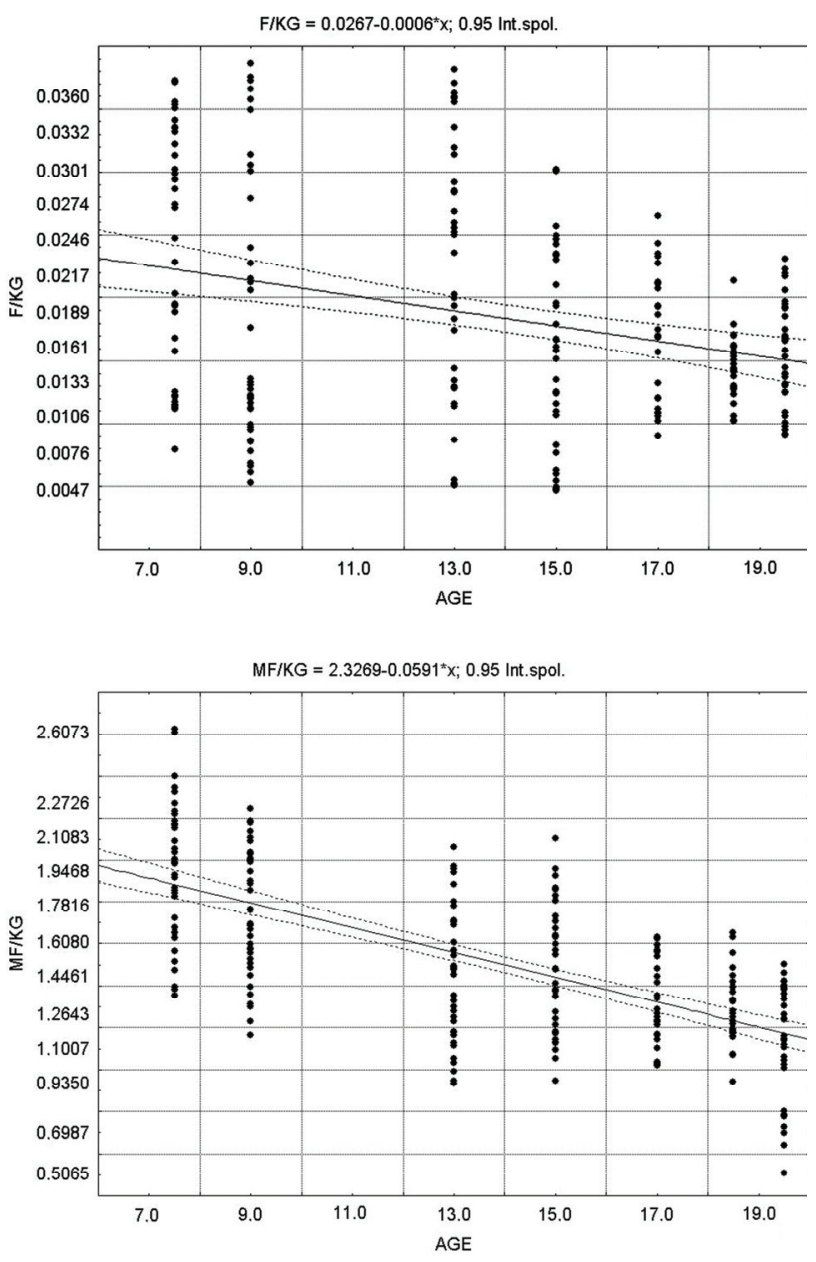

Fig. 5. The parameters as in Figure 4 related to $1 \mathrm{~kg}$ of the body weight. Two figures represent the systolic force $\mathrm{F} / \mathrm{kg}$ (upper part) and minute cardiac force MF/kg (lower part) (ordinate). Abscisse: age in years between 7-19 (girls). Decreasing linear relationship significance tested by Student test $p<0.0001$. Predictive equation is given on the head of each graph.

boys and adolescent boys measured with Q-BCG $(\mathrm{p}<0.001)$. Both parameters increased.

Figure 5 describes the relationship of age and the same parameters as in Figure 4 related to $1 \mathrm{~kg}$ of body weight $(\mathrm{F} / \mathrm{kg}, \mathrm{MF} / \mathrm{kg})$ in girls and adolescent girls. Both parameters decreased continuously $(\mathrm{p}<0.001)$.

Figure 6 describes the relationship of age of adult persons (men) between 20-60 years and absolute value of systolic force $(\mathrm{F})$ and relative value per $\mathrm{kg}$ of body weight $(\mathrm{F} / \mathrm{kg})$. Both values were decreasing with age $(\mathrm{p}<0.001)$.

Figure 7 describes changes of systolic force $(F)$ and minute cardiac force (MF in conditions of different $\mathrm{O}_{2}$ tension corresponding $6000 \mathrm{~m}$ above sea level till $30 \mathrm{~m}$ under the sea level.

Figure 8 describes changes of systolic force per $\mathrm{kg}$ of body weight $(\mathrm{F} / \mathrm{kg})$ measured by $\mathrm{Q}-\mathrm{BCG}$, of 

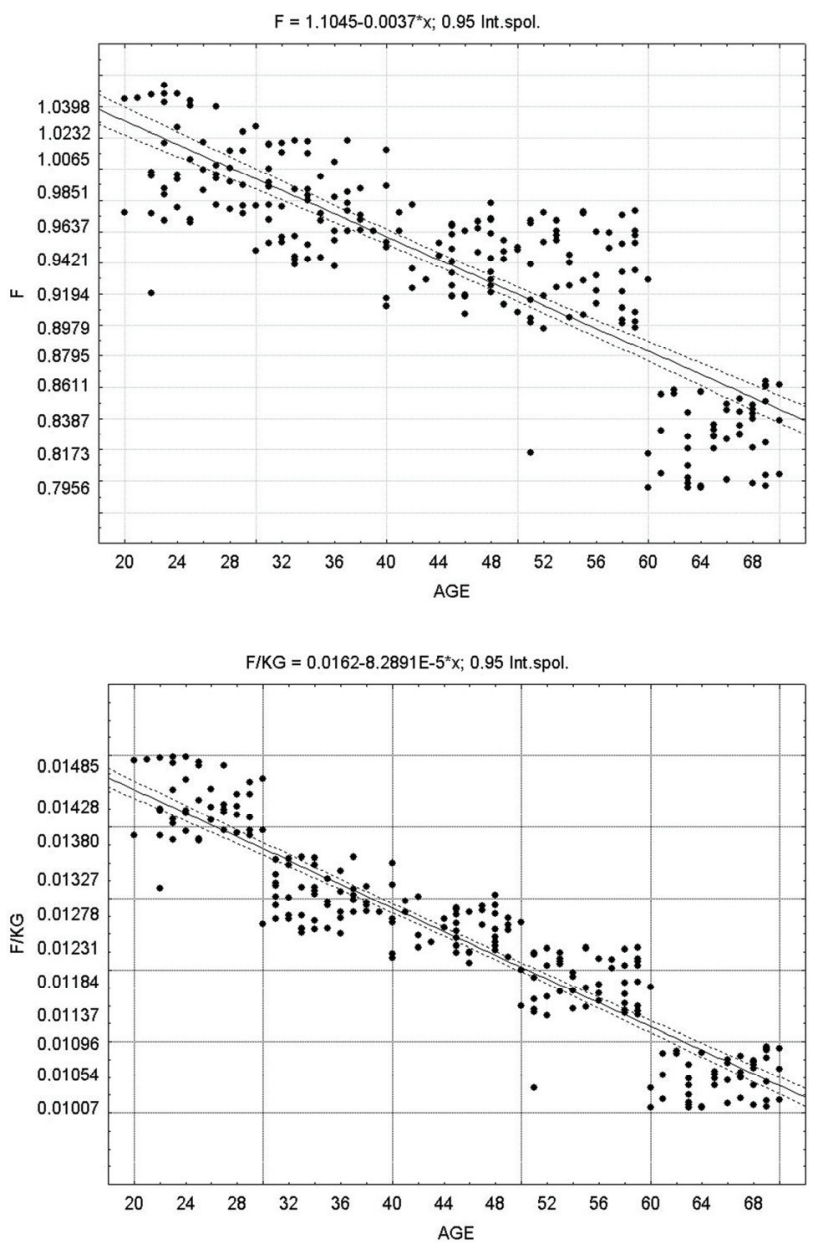

Fig. 6. Relationship between the systolic force ( $F$, upper part), systolic force per $\mathrm{kg}$ of the weight $(\mathrm{F} / \mathrm{kg}$, lower part) and between the age of adult persons (men) between 20-60 years. Abscisse: age in years, ordinate: force (Newtons - upper part), force per $\mathrm{kg}$ of the weight (lower part). Decreasing linear relationship significance tested by Student test $p<0.0001$. Predictive equation is given on the head of each graph.

acceleration index (ACI) measured by thoracic electrical bioimpedance (TEB) and ejection fraction (EF) measured by ECHO. All parameters measured by different noninvasive methods had the same trend - there were decreasing with increasing BMI or BSA in girls.

Figure 9 (left part) shows curves representing the relationship between the systolic force per $\mathrm{kg}$ of the body weight $(\mathrm{F} / \mathrm{kg})$ and graduated work load (L). In boy the steepest rise of the curve occurred at the work load of $120 \mathrm{~W}$. The maximum effort was reached at the work load of $240 \mathrm{~W}$ at which point the heart rate was 187 beats per min. In sedentary adult man the maximum rise of the curve appeared only at the work load of $180 \mathrm{~W}$ when the curve reached its peak. At the maximum work load of $300 \mathrm{~W}$ the heart rate was 180 beats per min. In athlete a continuous rise in the curve was observed up to the
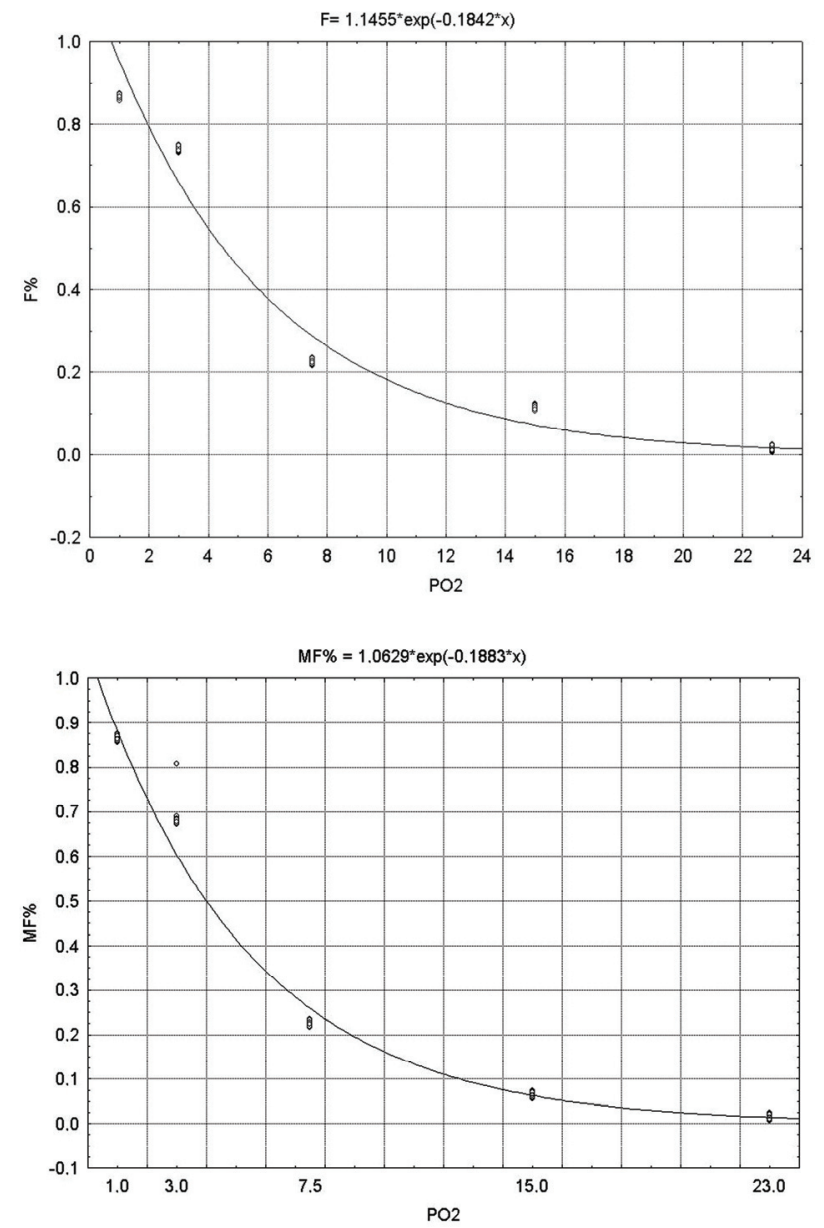

Fig. 7. Relationship between systolic force $F$ (upper part), minute cardiac force MF (lower part) (ordinate) and between partial tension of oxygen ( $\mathrm{mm} \mathrm{Hg}$, abscisse). Relationship between systolic force (F), minute cardiac force (MF) and partial tension of oxygen has exponential form. Predictive equation is given on the head of each graph. The F and MF are expressed in per cent of total change in hypoxia and hyperoxia. The most pronounced change was observed in the highest hypoxia $\left(\mathrm{pO}_{2}=0-8 \mathrm{~mm} \mathrm{Hg}\right)$.

maximum work load of $360 \mathrm{~W}$ at which point the heart rate was 180 beats per min. The final maximum heart rate in all three groups at the maximum applied work load was nearly the same. Evident differences between the groups were found in $\mathrm{F} / \mathrm{kg}$ at different work loads. The curves of Figure 9 (right part) illustrate the relationship between the minute cardiac force per $\mathrm{kg}$ of body weight $(\mathrm{MF} / \mathrm{kg}$ ) and the graduated work load (L). In boy a steep rise in the curve appeared at lower loads than in both other persons, and in athlete it occurred at much higher loads. In boy and in sedentary man a retardation of the rise of the curve - a leveling off - was apparent at higher values of the work load. In athlete even at work loads of $360 \mathrm{~W}$ no similar leveling off was observed. Comparison of the values of groups showed that during rest and the work load of $60 \mathrm{~W}$ the values in boys were the highest, 


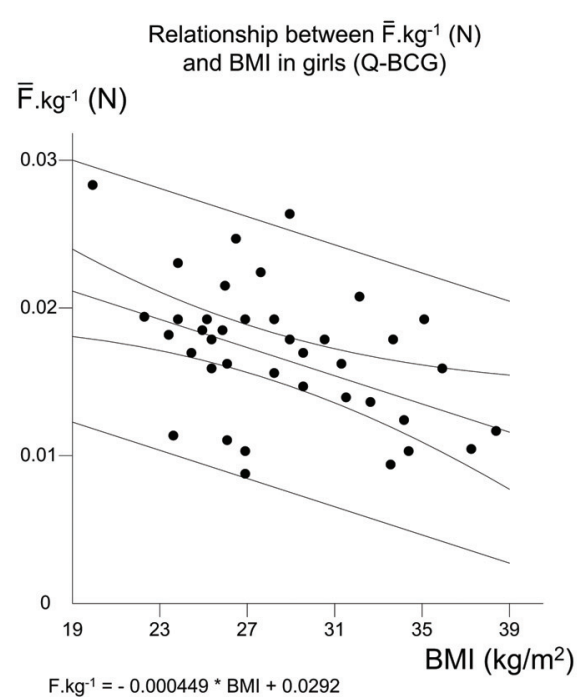

$$
\begin{aligned}
& F . \mathrm{kg}^{-1}=-0.0004 \\
& r=-0.4393 \\
& R-A D J=19.3 \% \\
& N=42
\end{aligned}
$$

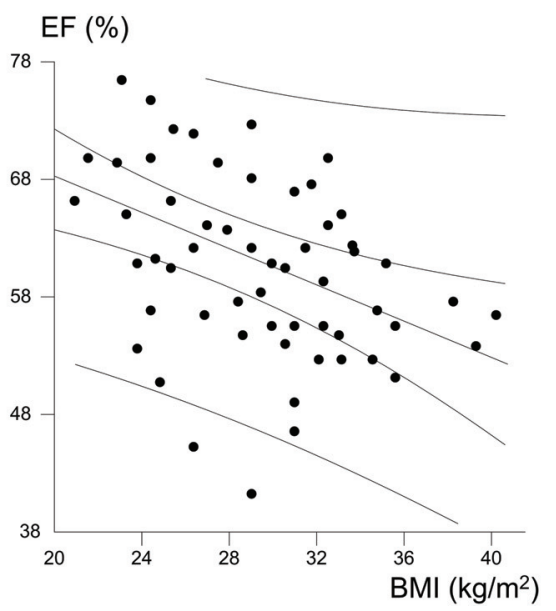

Relationship between $\mathrm{ACl}$ and $\mathrm{BMI}$ in girls (TEB)

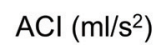

400

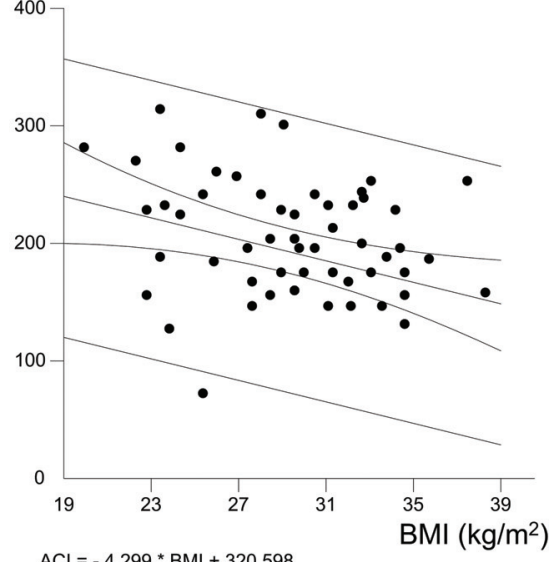

$\mathrm{ACl}=-4.299 * \mathrm{BMI}+320.598$

$\mathrm{r}=-0.3451$

$\mathrm{R}-\mathrm{ADJ}=11.91 \%$

$\mathrm{N}=42$
Fig. 8. Left upper part Relationship between systolic force/kg of body weight measured by Q-BCG and BMI in 42 girls. Abscisse: BMI $\left(\mathrm{kg} / \mathrm{m}^{2}\right)$. Right upper part - Relatioship between ACI (acceleration index) measured by thoracic electrical bioimpedance (TEB) and BMI in girls. Left lower part Relationship between ejection fraction (per cent) measured by $\mathrm{ECHO}$ and $\mathrm{BMI}$ in girls; $r=$ correlation coefficient; R-ADJ = percent of squares of standard deviations. whereas in sedentary men and athletes the values were lower and did not differ. At the work load of $240 \mathrm{~W}$ the $\mathrm{MF} / \mathrm{kg}$ of athletes was not very much more than a half ( $58 \%$ ) of the value found in boys and sedentary adults.

The relationship between heart weight (HW data from the literature) and hand grip force (HGF) increased in boys between 8-14 years of age by the linear shape (Fig. 10, left part). There is a linear corelation between the systolic force measured by Q-BCG and hand grip force measured by manual dynamometer at the same group (Fig. 10, right part).

\section{Discussion}

Ballistocardiograhy is the method which studies the mechanical effects of the circulatory system acting on the body. The oscillations of the ballistocardiographic devices are often similar to the cardiac frequency and provoke the interferences so that the curve is the summation of signals of the device and of the heart. The further deformation of the resulting curve is the damping of oscillatory systems in the apparatus.

In 1952 we began to construct the quantitative ballistocardiograph where the examined person was in sitting position (Trefný and Smetánka 1956). We did not examine the persons in a lying position which is inconvenient on account of the compliance of muscles, fat and skin and their compliant connection to the bones. This layer makes the examined person unable to rest quite firmly upon the table. Thus a further vibrating system originates which interferes with the vibrations caused by heart activity.

For this reason we decided to examine the persons in a sitting position. In this case the pelvic bones are in close contact with the chair and the coupling of the examined person and the instrument is much better. In this way the damping of implied vibrations is minimal. Another advantage of the vertical position is fact that the vibrations due to the heart activity are transmitted with minimal loss as the crystal is situated just below the 

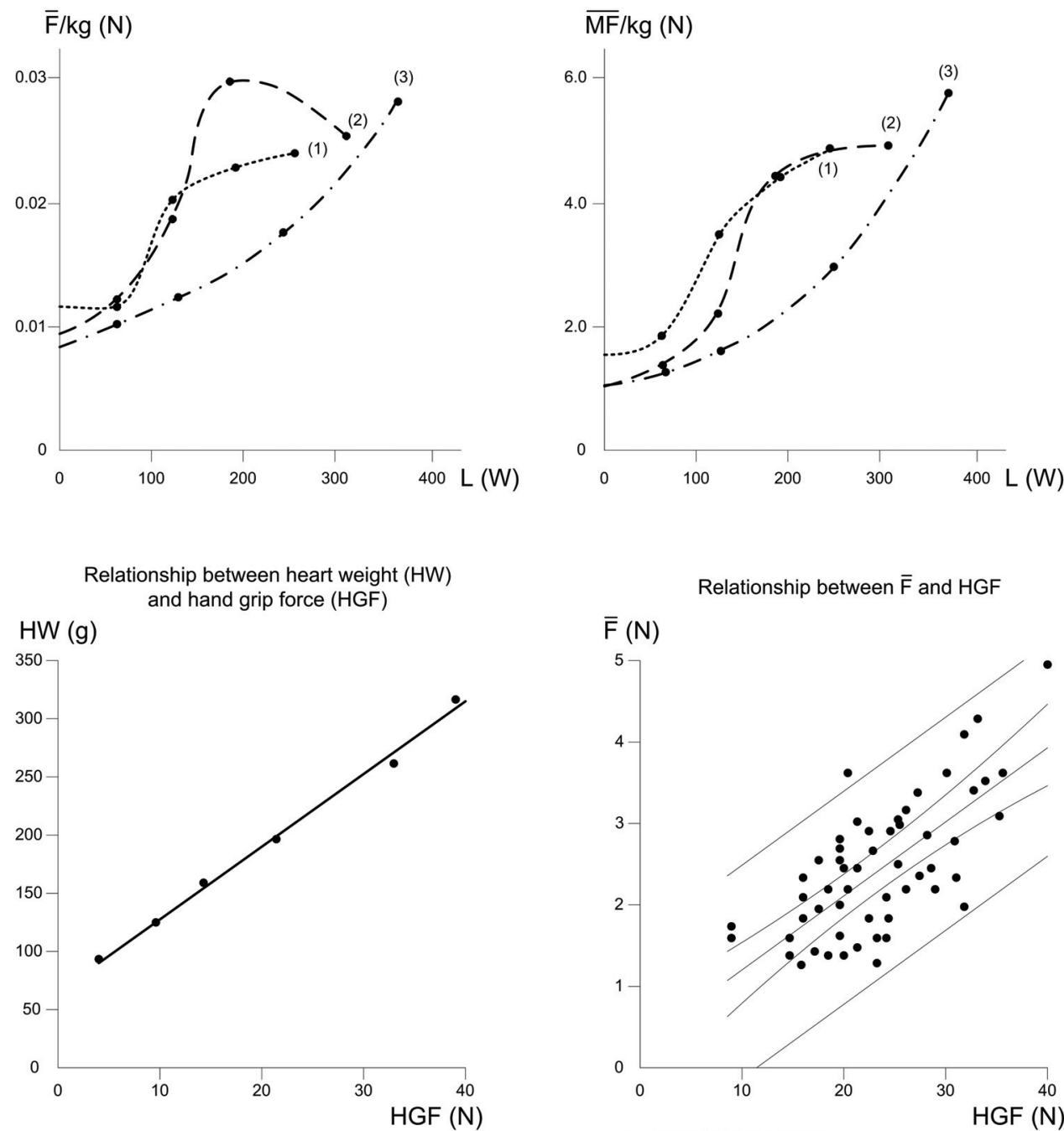

center of gravity of the body.

New methods, such as myocardial tagging based on magnetic resonance (MR) imaging allow the noninvasive assessment of the three-dimensional motion of the heart (Nagel et al. 1995, 1996), but the heart force was not measured.

The comparison of Figures 4, 5 and 6 showed that the absolute values of $F$ (Fig. 4, upper part) increased in boys between 7-19 years, while in adults between 20-60 years it decreased (Fig. 6, upper part). The parameters $\mathrm{F} / \mathrm{kg}$, and $\mathrm{MF} / \mathrm{kg}$ decreased both in girls (Fig. 5, lower part) between 7-19.5 years and in adults (Fig. 6). Similar changes of $\mathrm{F}$ and MF were observed in each series of examined persons. It was concluded that absolute values of both $\mathrm{F}$ and MF increased in growing organism from 7 to 19.5 years and decreased in adults from 20 to 60 years. Both parameters related to $\mathrm{kg}$ of body weight decreased in all measured groups of persons.
Fig. 9. Relationship between systolic force per $\mathrm{kg}$ of body weight $(\mathrm{F} / \mathrm{kg})$, minute cardiac force per $\mathrm{kg}$ of body weight $(\mathrm{MF} / \mathrm{kg}$, right part) and graduated work load in boys (1), adult sedentary men (2) and in athlets (3). The $\mathrm{F} / \mathrm{kg}$ (left part) and MF/kg (right part) was expressed in Newtons (ordinate, N), the work load in Watts (abscisse). The work load was measured in bicycle ergometry and $\mathrm{F}$ and MF measured by Q-BCG. Results of one experiment from the series of 30 experiments.

Fig. 10. Relationship between heart weight $(\mathrm{HW})$ data from the literature and hand grip force (HGF) (in Newtons) in 49 boys, age 8-14 years. The hand grip force was measured by manual dynamometer (left part). The relationship between systolic force (F) and HGF (right part) in the same group of boys.
The increase of the systolic force $(\mathrm{F})$ in the range of the decrease of $\mathrm{pO}_{2}$ (Fig. 7) is relatively small so that the increase of minute cardiac force (MF) depends in a greater degree on the increase of the heart rate (HR). The resulting effect is evidently influenced by two antagonist factors. The decreased oxygen tension has a direct and indirect depressive influence upon the heart muscle (Gremels et al. 1965). On the other hand, the intact organism reacts to hypoxia by an increase of the contractions of the heart muscle and by an increase of the cardiac output. The compensatory effect of the heart rate (HR) at a small increase of the systolic force (F) is in this situation evident. We explain it by the fact that this function is a complex expression of two regulated quantities, namely the systolic force (F) and heart rate. The minute cardiac force (MF) is a more complex picture of the circulatory response to the changes of $\mathrm{pO}_{2}$.

A group of children was examined using three 
different noninvasive methods: Q-BCG, TEB, ECHO (Fig. 8). With increasing BMI/BSA (both values measured from the same parameters, body weight and height) there was the decrease of $\mathrm{F} / \mathrm{kg}$, ACI and ejection fraction (EF) (Šrámek 1993, Trefný et al. 2004, Schuster et al. 2009).

Different non-invasive methods are able to yield specific informations which are supplementary and which deepen our knowledge about the general picture of cardiovascular dynamics. Every method in relation to another one gives a systematically higher or lower value and the real value remains undiscovered. No single method may be considered as the ,golden standard“. These methods are not in competition, but mutually support each other when working in cooperation with each other.

The systolic force (F) describes the force response caused by the heart activity to the applied work load (Fig. 9). The minute cardiac force (MF) describes the total intensity of the heart activity. A comparison of $F$ anf MF shows that there exist a compensatory mechanism between the $F$ and heart rate (HR): if the F decreases, the HR increases, so that the M F does not decrease with increasing work load. From the F and MF curves we can estimate at which work load the compensation begins to work (Trefný and Seliger 1968).

The $\mathrm{F}$ curves show characteristic differences in subjects of different physical fitness (Fig. 9). It is our opinion that the minute cardiac force response may serve as a criterion of physical fitness and, at the same time the Q-BCG method appears to be useful in the attempt to elucidate certain basic principles of the heart activity (Trefný et al. 1968).

It was found that there is a linear relationship between heart weight (according to literature) and hand grip force (Fig. 10). The linear relationship between systolic force and skeletal muscle force in growing organism showed that both cardiac muscle force and skeletal muscle force are regulated by the same neurohumoral mechanisms. According to our opinion it was not proved formerly (Fig. 10).

Doing a google scholar search on the term Ballistocardiography provides around 10 works per year before 2000 and more than 50 per year since 2008, while no reference have been found about the Q-BCG until now to compare it with our results. But the other noninvasive methods as echocardiography, radionuclide ventriculography, thoracic electrical bioimpedance (TEB) are capable to measure cardiac output, ejection fraction, ventricular end-diastolic volume, ventricular filling and systolic function. The methods confirmed our Q-BCG method (Port et al. 1980, Corallo et al. 1981, Steiger et al. 1987, Adams et al. 1992). Both the systolic (F) and the minute cardiac force (MF) are the physiological parameters regulated by the neurohumoral mechanisms similarly as the heart rate or the systolic output. F and MF are regulated by the same way as the other physiological functions.

The Q-BCG method appeared to be a useful method of measurement of $\mathrm{F}$ and MF in the attempt to elucidate the basic principles of cardiac function.

\section{Conflict of Interest}

There is no conflict of interest.

\section{Acknowledgements}

The authors will thank to Mrs Tereza Vavř́k ková for kind preparation of text and figures. Supported by grant MŠMT OE008001.

\section{References}

ADAMS KF JR, MCALLISTER SM, EL-ASHMAWY H, ATKINSON S, KOCH G, SHEPS DS: Intrrelationships between left ventricular volume and output during exercise in healthy subjects. J Appl Physiol 73: 2097-2104, 1992.

CORALlO S, BROSO G, PIRASTU A, SEGA R, BOZZI G, GARIMOLDI M, RAVAGNAN S, CASTELFRANCO M: Echocardiographic study of left ventricular performance during sitting bicycle exercise. G Ital Cardiol 11: 1072-1082, 1981.

GORDON JW: On certain molar movements of the human body produced by circulation of the blood. J Anat Physiol 11: 533-568, 1877.

GREMELS H, STARLING EH, PODER T, LAMB TV: Physiological consequences of hypoventilation and hyperventilation. In: Handbook of Physiology, Section 3: Respiration. American Physiological Society, Washington, D.C., 1965, pp 979-1010. 
HAMILTON WF, DOW P, REMINGTON JW: The relationship between the cardiac ejection curve and the ballistocardiographic forces. Am J Physiol 144: 537-554, 1945.

HAMILTON WF: Measurement of cardiac output: ballistocardiography. In: Handbook of Physiology, Section 2: Circulation, vol. 1. American Physiological Society, Washington D.C., 1962, pp 562-565.

HARVEY W: Exercitatio anatomica de motu cordis et sanguinis in animalibus. Frankfurt, 1628.

HENDERSON Y: The mass-movements of the circulation as shown by a recoil curve. Am J Physiol 14: 287-296, 1905.

JACKSON DH: A brief critique of the direct body ballistocardiographic method. Bibl Cardiol 29: 29-34, 1972.

NAGEL E, STUBER M, FISCHER SE, BOESIGER P, HESS OM: Myocardial tagging: a new method for the analysis of left ventricular motion. Circulation 92 (Suppl): I-509, 1995.

NAGEL E, STUBER M, MATTER C, LAKATOS M, BOESIGER P, HESS OM: Rotational and translational motion of the heart after myocardial infarction. J Cardiovasc Pharmacol 28 (Suppl 2): S31-S35, 1996.

NICKERSON JL, CURTIS HJ: The design of the ballistocardiograph. Am J Physiol 142: 1-5, 1944.

PORT S, COBB FR, COLEMAN RE, JONES RH: Effect of age on the response of the left ventricular ejection fraction to exercise. N Engl J Med 303: 1133-1137, 1980.

SCHUSTER I, KARPOFF L, PEREZ-MARTIN A, OUDOT C, STARTUNA A, RUBINI M, OBERT P, VINET A: Cardiac function during exercise in obese prepuberta boys: effect of degrese of obesity. Obesity (Silver Spring) 17: 1878-1893, 2009.

STARR I, NOORDERGRAAF A: Ballistocardiography in Cardiovascular Research. J.B. Lippincott Comp., Philadelphia/Montreal, 1967.

STEIGER J, SIMON G, PAUER A, KEUL J: Echocardiographic contractility reserve and invasive hemodynamics in physical stress in probands with healthy hearts and patients with dilated cardiomyopathy (in German). Z Kardiol 76: 635-642, 1987.

ŠRÁMEK BO: Thoracic electrical bioimpedance: Basic principles and physiologic relationships (in Czech). Čs Fyziol 42: 111-115, 1993.

TREFNÝ Z: Arrangement for ballistocardiographic registration of efficiency in circulation. Patent No. 113490, Institute of Patents and Inventions, Prague, 1962.

TREFNÝ Z: Some physiological aspects in quantitative ballistocardiography. Bibl Cardiol 26: 116-118, 1970.

TREFNÝ Z, SMETÁNKA E: A new principle in the use of piezoelectricity in ballistocardiography (in German). Physiol Bohemoslov 5: 487-489, 1956.

TREFNÝ Z, WAGNER J: Problem of quantitative ballistocardiography (In Czech). Čs Fysiol 14: 5-15, 1965.

TREFNÝ Z, WAGNER J: The new ballistocardiographical system and the clinical ballistocardiography in children. Proc. 1st World Congr. Ballistocard. Cardiovasc. Dynamics, Amsterdam, 1965, Karger, Basel/New York, 208-212, 1966.

TREFNÝ Z, WAGNER J: A quantitative ballistocardiograph. Bibl Cardiol 19: 19-25, 1967.

TREFNÝ Z, SELIGER V: The use of quantitative ballistocardiography for the measurement of the working capacity of the circulatory system in the graduated work load. Bibl Cardiol 20: 106-109, 1968.

TREFNÝ Z, WAGNER J, SELIGER V, BUCHBERGER J: Force measurements in adults and schoolchildren by a quantitative ballistocardiographic method. Bibl Cardiol 21: 152-156, 1968.

TREFNÝ Z, SVAČINKA J: Effect of hypoxia and hyperoxia on the quantitative ballistocardiogram. Bibl Cardiol 26: 119-124, 1970.

TREFNÝ Z, POLÁČEK M, NĚMEC J: Physical properties of the portable quantitative ballistocardiography. Physiol Bohemoslov 19: 351, 1970.

TREFNÝ Z, SLAVÍČEK J, POLÁČEK M: Evaluation of a mathematical basis for a circuit serving as a correction to the transfer function of the human body in the quantitative ballistocardiogram. Bibl Cardiol 29: 107-110, 1972.

TREFNÝ Z, TICHÝ JA, HOJEROVÁ M, FIŠÁRKOVÁ B, LOUČKA M, SVAČINKA J, TREFNÝ M, TROJAN S, SLAVÍČEK J, HERCZEGH Š: Cardiovascular dynamics in obese children (in Czech). Čes-slov Pediatrie 59: 283-291, 2004. 